paciente, que dificultan el diagnóstico anatomopatológico y obligan a descartar, entre otras, la existencia de tumor carcinoide testicular. En el momento actual se desconocen las implicaciones clínicas de este hallazgo casual.

El tratamiento habitual de estas lesiones es la orquiectomía inguinal, acompañada de linfadenectomía retroperitoneal si se demuestran crecimientos ganglionares en los casos malignos ${ }^{9}$, así como poliquimioterapia sistémica y radioterapia (normalmente con pronóstico ominoso). Existen casos descritos en la literatura médica en los que se ha realizado cirugía conservadora (tumorectomías) en casos bilaterales, en varones prepuberales ${ }^{10}$ o en casos claramente benignos como en el nuestro. Es necesario un seguimiento a largo plazo debido a que se han descrito metástasis incluso a los 15 años desde el tratamiento. Debido a lo inusual de esta patología no existe una pauta para seguir, aunque sí se recomienda la realización periódica de análisis con marcadores tumorales (AFP, BhCG, LDH) hormonas (estrógenos, progesterona y testosterona), exploración física y TAC toracoabdominal.

La baja incidencia y el relativo desconocimiemto a largo plazo de este tipo de tumores, así como el hallazgo excepcional de características de neurosecreción en nuestro tumor y las escasas referencias en la literatura médica al respecto ${ }^{8}$, nos plantea la duda de si realmente este hecho pudiera ser clínicamente significativo o un hallazgo meramente casual.

B I B L I O G R A F Í A

1. Young RH, Koelliker DD, Scully RE. Sertoli cell tumors of the testis, not otherwise specified: A clinicopathologic analysis of 60 cases. Am J Surg Path. 1988;22:709.

2. Domínguez Molinero JF, Vergara Alcaide E, Fernández Rodríguez A, Nogueras Ocaña M, Martínez Torres JL, Zuluaga Gomez A.
Tumor testicular de células de Sertoli: variedades clínicas patológicas. A propósito de un caso. Act Urol Esp. 1997 519-23.

3. Chang B, Borer JG, Tan PE, Diamond D. Large-cell calcifying Sertoli cell tumor of the testis: Case report and review of the literature. Urology. 1998;52:520-2.

4. Giglio M, Medica M, Franco de Rose A, Germinale F, Ravetti JL, Carmigiani G. Testicular Sertoli cell tumours and relative subtypes. Analysis of clinical and prognostic features. Urol Int. 2003;70.

5. Werther M, Schmelz HU, Schwerer M. Sclerosing Sertoli cell tumor of the testis: A rare tumor. Case report and review of the literature on the subtypes of Sertoli-cell tumor. Urologe A. 2007;46:1551-6.

6. Henley JD, Young RH, Ulbright TM. Malignant Sertoli cell tumors of the testis: A study of 13 examples of a neoplasm frequently misinterpreted as seminoma. Am J Surg Pathol. 2002;26:541-50.

7. Azurmendi I, Llarena R, García-Olaverri J, Olano I, Cantón E, Pertusa C. Tumor de células de Sertoli maligno. Arch Esp Urol. 2008;61:834-7.

8. Kuroda N, Senzaki T, Yamasaki Y, Miyazaki E, Hayashi Y, Toi M. Sertoli cell tumor of the testis (not otherwise specified) with the expression of neuroendocrine markers and without the expression of inhibin-alpha. Pathol Int. 2004;54: 719-24.

9. Featherstone JM, Fernando HS, Theaker JM, et al. Sex cord stromal testicular tumors: A clinical series-uniformly stage I disease. J Urol. 2009;181:2090-6.

10. Valla JS. Testis sparing surgery for benign testicular tumors in children. J Urol. 2001;165:2280-3.

\section{J.D. Jiménez ${ }^{a}$,* J.L. Cebrián ${ }^{a}$, R. Guarch ${ }^{b}$ y A. Hualde ${ }^{a}$}

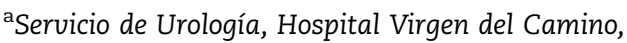
Pamplona, España

bervicio de Anatomía Patológica, Hospital Virgen

del Camino, Pamplona, España

*Autor para correspondencia.

Correo electrónico: jdjimenez@hotmail.es (J.D. Jiménez).

\title{
Leiomioma bilateral y asincrónico de epidídimo: presentación de un caso
}

\section{Bilateral and metachonous leiomyoma of the epidydimo: a case report}

\section{Sr. Director:}

Presentamos el caso clínico de un leiomioma de epidídimo bilateral de aparición asincrónica. Hemos realizado una revisión de los casos publicados en los últimos diez años analizando el diagnóstico, el tratamiento y el seguimiento.

Los leiomiomas de epidídimo son tumores benignos y poco habituales en la práctica clínica diaria. Representan el segundo grupo de tumores paratesticulares, siendo solo el $15 \%$ bilaterales.
Paciente varón de 60 años que acudió a la consulta externa derivado del médico de familia por elevación del antígeno prostático específico (PSA). El paciente refería antecedentes de orquiectomía por un tumor benigno de testículo, además de hipertensión arterial. Revisando el historial clínico, había sido intervenido hacía tres años por una masa paraescrotal derecha de $4 \mathrm{~cm}$ de diámetro máximo, practicándosele orquiectomía derecha más colocación de prótesis de silicona. El resultado del estudio anatomopatológico reveló una masa fusiforme de $4 \mathrm{~cm}$, localizada en la cola del epidídimo derecho, que fue 
etiquetada de leiomioma de epidídimo. Tras un período de revisión de dos años, el paciente fue dado de alta.

El paciente aportaba una analítica sanguínea en la que únicamente destacaba una elevación del PSA, con un valor total de $6,25 \mathrm{ng} / \mathrm{ml}$ y una ratio del $14 \%$. Durante la exploración física detectamos una tumoración no dolorosa a la palpación, a nivel de la cabeza del epidídimo izquierdo, de aproximadamente $2 \mathrm{~cm}$ de diámetro, de consistencia indurada y bordes bien definidos. El resto de la exploración no reveló patología, apreciándose una próstata pequeña, de consistencia adenomatosa y sin nódulos al tacto rectal.

Se solicitó una biopsia de próstata ecodirigida y por vía transrectal, así como una ecografía testicular. La biopsia prostática informó de la existencia de un adenocarcinoma de próstata grado 3+3/10 de Gleason en el 25\% del lóbulo derecho en uno de 5 cilindros sin infiltración perineural. En el lóbulo izquierdo no se observaba malignidad. En la ecografía testicular se objetivaba una tumoración sólida de $1,9 \mathrm{~cm}$ a nivel de la cabeza del epidídimo izquierdo, sin lesiones en el testículo homolateral ni en la prótesis.

Con estudio preoperatorio correcto, al paciente se la practicó una incisión media infraumbilical seguida de disección del cordón espermático y del testículo izquierdo a través del canal inguinal. Se realizó la exéresis completa de una masa sólida, de aspecto carnoso, de $2 \mathrm{~cm}$, que se envió como estudio patológico peroperatorio. Confirmada la presencia de un leiomioma, se procedió a la recolocación del testículo en la bolsa escrotal y se finalizó la prostatectomía radical.

El paciente fue dado de alta hospitalaria a los 8 días del postoperatorio sin incidencias.

El resultado definitivo de las muestras de epidídimo y próstata fue el siguiente: leiomioma de epidídimo y adenocarcinoma de próstata Gleason $3+3 / 10$ en la totalidad del lóbulo derecho, que afectaba focalmente al lóbulo izquierdo con invasión perineural y de la grasa periprostática (pT3a).

Dos años después de la intervención, el paciente presenta un buen confort miccional sin incontinencia de esfuerzo. Tampoco ha presentado alteraciones a nivel testicular en la exploración física ni a nivel ecográfico. Las cifras de PSA se mantienen por debajo de $0,01 \mathrm{ng} / \mathrm{ml}$ y los niveles de testosterona total son normales $(4,97 \mathrm{ng} / \mathrm{ml})$.

Los leiomiomas de epidídimo son tumores poco frecuentes y constituyen el segundo grupo de tumores benignos paratesticulares ${ }^{1}$ después del tumor adenomatoide. Generalmente son unilaterales, pero una revisión de 29 casos publicados en los últimos 10 años nos muestra que el $14 \%$ de los casos fueron bilaterales. La mayoría de los casos publicados fueron tumores sincrónicos, siendo la presentación en nuestro caso clínico asincrónica.

Generalmente se presentan en la quinta década de la vida. La localización en la mayoría de los casos publicados fue el epidídimo (87\%), pero se han descrito leiomiomas en la túnica albugínea $(4 \text { casos }[10 \%])^{2-4}$ y en el teste $(1 \text { caso }[3 \%])^{5}$.

El diagnóstico se suele iniciar mediante la palpación. Se trata de masas induradas, bien delimitadas e indoloras ${ }^{6,7}$. El método diagnóstico más recomendado por los diferentes autores es la ecografía ${ }^{4-8}$. Los leiomiomas se describen como lesiones hipoecogénicas, bien delimitadas y con finas sombras acústicas. En nuestro caso, el informe ecográfico sólo reveló la naturaleza sólida y bien delimitada del tumor

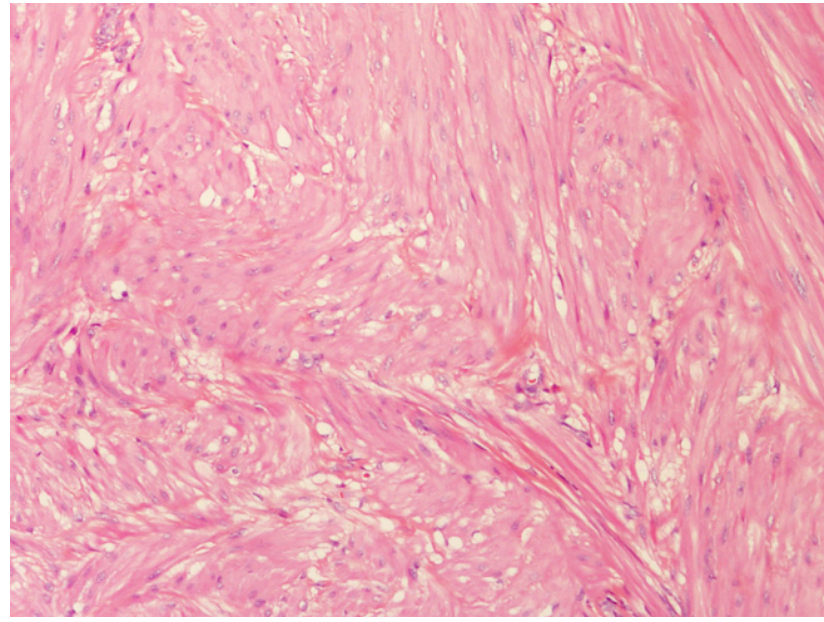

Figura 1 - Tumoración mesenquimal formada por células en husos entrelazados separadas por bandas fibrosas (HE $10 \times$ ).

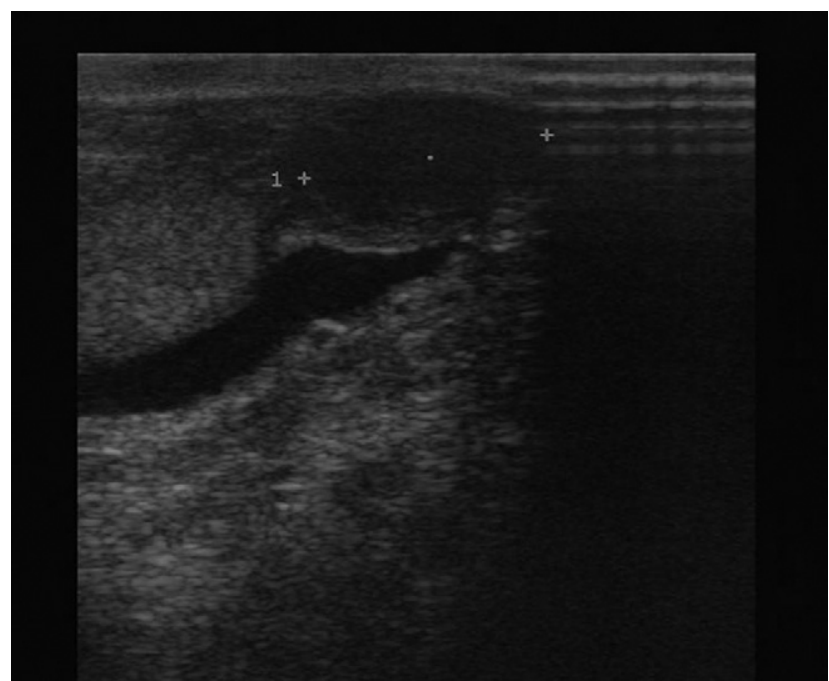

Figura 2 - Ecografía testicular que muestra tumoración sólida de $1,9 \mathrm{~cm}$ a nivel de la cabeza del epidídimo izquierdo.

(fig. 1) ${ }^{4}$. Los diferentes autores coinciden en que las imágenes ecográficas no siempre son concluyentes, recomendándose la exéresis quirúrgica $^{4-8}$.

En el estudio anatomopatológico se describen como tumoraciones formadas por haces de células lisas sin presencia de atipias, tal como se presenta en nuestro caso (fig. 2), aunque se ha descrito un caso con alteraciones nucleares ${ }^{9}$.

Con respecto al tratamiento, la mayoría de los autores (70\%) realizaron una exéresis simple o una epididimectomía parcial. Solo hemos encontrado 3 casos en los que se practicó una orquiectomía y fue por motivos como la sustitución casi completa del parénquima $\mathrm{sano}^{5}$, la presencia de núcleos aberrantes $^{9}$ o la asociación a multiples hamartomas en testes atróficos en un paciente con síndrome feminizante testicular ${ }^{2}$. A nuestro paciente se le había realizado previamente una orquiectomía derecha con colocación de prótesis por presentar una tumoración de $4 \mathrm{~cm}$, por lo que la cirugía conservadora era 
en el caso del epidídimo izquierdo muy necesaria para evitar el tratamiento de sustitución hormonal crónico.

Ninguno de los casos que hemos revisado han presentado evidencia de recidiva o diseminación, por lo que el tratamiento conservador no compromete el pronóstico de la enfermedad. Nuestro paciente está libre de enfermedad 2 años después de la cirugía, tal como lo demuestra el control ecográfico. No creemos que sea necesario un seguimiento a largo plazo para los casos unilaterales. En casos bilaterales, una valoración de la función hormonal parece apropiada.

Los leiomiomas de epidídimo son tumores poco frecuentes pero pueden presentarse en la práctica clínica diaria. El diagnóstico se basa en la palpación y el estudio ecográfico. Debido al excelente pronóstico, la exéresis podría obviarse, pero la ecografía no suele ser suficientemente fiable para el diagnóstico definitivo, por lo que la exéresis quirúrgica completa es el tratamiento más recomendable cuando nos enfrentamos a una masa sólida paratesticular. Una vez que conocemos que se trata de un leiomioma hay que evitar los tratamientos agresivos dado que, como en nuestro caso, puede aparecer otro tumor en el epidídimo contralateral, incluso años después.

\section{Agradecimientos}

Al Servicio de Anatomía Patológica y concretamente a la jefa de servicio, la Dra. Carme Admella Salvador.

B I B L I O G R A F Í A

1. Attignac P, Enarard P, Debre B. Kystes et tumeurs de l'epididyme. Encicl Med Chir (París). Rein organes genitourinaires. 1984;B10:1865.
2. Krichen Maken S, Mnif Hachicha L, Ellouze S, et al. Femizing testicular syndrome with multiple hamartomas and bilatera paratesticular leiomyomas. Rev Med Interne. 2005;26: 980-3.

3. Forte F, Scartini M, Spera E, et al. Leiomyoma of the epididymis and testicular anexa: Apropos of 3 cases. Arch Ital Urol Androl. 2004;76:119-20.

4. Mack CW, Tzeng WS, Chou CK, et al. Leiomyoma arising from the tunica albuginea of the testis: Sonographic findings. J Clin Ultrasound. 2004;32:309-11.

5. Destito A, Serrello C, Pisanti F, et al. Leiomyoma of the testis. Scand J Urol Nephrol. 1999;33:338-9.

6. Larbcharoensub BN, Sornmayura P, Ariyaprakai W. Bilateral leiomyoma of the epidydimimes. J Med Assoc Thai. 2006;89: 1051-1054.

7. Fumo MJ, Assi QA, Liroff S. Leiomyoma of the epididymis treated with partial epididimectomy. Nat Clin Pract Urol. 2006;3:504-7.

8. Cuesta Alcalá JA, Arrondo Arrondo JL, Pascual Piédrola I, et al. Diagnóstico diferencial del leiomioma de epidídimo. Aportación de un nuevo caso. Arch Esp Urol. 2001;54: 823-5.

9. Borri A, Nesi G, Bancini L, Pernice LM. Bizarre leiomyoma of the epididymis. A case report. Minerva Urol Nefrol. 2000;52: 29-31.
J. Llopis Manzanera ${ }^{a, *}$, C. Ramírez Sevilla ${ }^{a}$,
C. Ferrer Cassadób y J.A. Romero Martin ${ }^{a}$

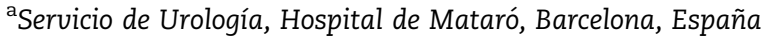

bservicio de Anatomía Patológica, Hospital de Mataró, Barcelona, España

*Autor para correspondencia.

Correo electrónico: jllopis@csdm.es (J. Llopis Manzanera).

\section{Lactante con estenosis de uréter medio congénito tratado endourológicamente}

\section{Endourological treatment of congenital midureteral stricture in an infant}

\section{Sr. Director:}

Presentamos el caso de un lactante derivado a nuestra unidad por diagnóstico prenatal de hidronefrosis derecha severa y riñón contralateral normal. En las exploraciones realizadas en las primeras semanas de vida se objetivó una hidronefrosis derecha severa. La cistouretrografía miccional fue normal. En el seguimiento, las ecografías mostraron un aumento progresivo de la dilatación renal derecha con dilatación de todos los grupos caliciales y adelgazamiento progresivo del parénquima renal, llegando a ser de $3 \mathrm{~mm}$. Además, se observó un uréter proximal muy dilatado y tenso (fig. 1). El renograma diurético a los 4 meses de vida mostró una disminución de la función renal diferencial derecha $(40 \%)$ con un patrón muy obstructivo. El lactante se mantuvo asintomático.

Se realizó una pielografía retrógrada con tutor ureteral de 4 Fr, encontrando una estenosis severa de uréter medio derecho con importante dilatación del uréter preestenótico. Tras lograr el paso de una guía de 0,014" hasta la pelvis renal derecha, se realizó una dilatación con balón de alta presión 